\title{
Erratum to: Encyclopedia of Educational Philosophy and Theory
}

Michael A. Peters

\section{Erratum to:}

M.A. Peters (ed.), Encyclopedia of Educational Philosophy and Theory, https://doi.org/10.1007/978-981-287-588-4

Owing to an unfortunate oversight the first published version of these entries contained an error regarding the authorship which has now been corrected.

Nietzsche's Schopenhauer and Education: The author name is corrected as Peter Fitzsimons and affiliation is updated.

Human Capital Theory and Education: The second incorrect affiliation of Patrick Fitzsimons is removed.

Managerialism and Education: The second incorrect affiliation of Patrick Fitzsimons is removed.

Metaphor and Edusemiotics: The first incorrect affiliation of Peter Fitzsimons is removed.

FM: The affiliation details of Peter Fitzsimons and Patrick Fitzsimons is updated as below in the "List of Contributors".

Peter Fitzsimons

Education and Management Services (NZ) Ltd., Auckland, New Zealand

Patrick Fitzsimons

Independent Researcher, Auckland, New Zealand

The online version of the updated original entries can be found at

https://doi.org/10.1007/978-981-287-588-4_350

https://doi.org/10.1007/978-981-287-588-4_331

https://doi.org/10.1007/978-981-287-588-4_341

https://doi.org/10.1007/978-981-287-588-4_22

https://doi.org/10.1007/978-981-287-588-4 